\title{
PREGUNTAS NO ADMITIDAS EN EL INTERROGATORIO LABORAL DE TESTIGOS
}

\author{
QUESTIONS NOT ALLOWED IN THE LABOR INTERROGATION \\ OF WITNESSES
}

ISAÍAS RODRÍGUEZ REYES*

\section{RESUMEN}

El escueto desarrollo normativo sobre qué tipos de preguntas pueden objetarse en la rendición de una prueba testimonial laboral, ha generado la existencia de diversas clasificaciones doctrinales de interrogantes que correspondería inadmitir en el curso de una audiencia de juicio. Con el propósito de caracterizar la facultad de objetar preguntas en un interrogatorio, se decidió aplicar el "método de casos" en el análisis de declaraciones testimoniales. En efecto, se realizó un estudio del ejercicio práctico de las objeciones efectuadas en cien audiencias de juicios aleatorias seguidas ante el Primer Juzgado de Letras del Trabajo de Santiago. Bajo dicha base de datos, pudo efectuarse un análisis con el propósito de determinar cuáles son las restricciones prácticas que mantiene actualmente el interrogatorio de testigos en materia laboral.

Palabras clave: Testigos, Interrogatorio de testigos, Preguntas no admitidas, Objeciones, Proceso laboral, Juicio Oral, Derecho laboral.

\footnotetext{
* Licenciado en Derecho de la Pontificia Universidad Católica de Chile. Magíster en Derecho del Trabajo y de la Seguridad Social de la Universidad de Chile. Profesor del Departamento de Práctica y Asistencia Legal de la Facultad de Derecho, Pontificia Universidad Católica de Chile, Santiago, Chile. Correo: iorodrig@uc.cl. ORCID: https://orcid.org/0000-0001-8386-889X.

Trabajo recibido el 9 de julio de 2021 y aprobado para su publicación el 14 de diciembre de 2021.
} 


\section{ABSTRACT}

The brief normative development on what types of questions can be objected in the rendering of a labor testimonial test, has generated various doctrinal classifications of questions that should be inadmissible in the course of a trial hearing. In order to characterize the power to object to questions in an interrogation, it was decided to apply the "case method" in the analysis of testimonial statements. Indeed, a study was carried out of the practical exercise of the objections made in one hundred random trial hearings followed before the First Labor Court of Santiago. Under said database, an analysis could be carried out in order to determine the practical restrictions that currently maintain the questioning of witnesses in labor matters.

Keywords: Witnesses, Examination of witnesses, Questions not admitted, Objections, Labor process, Oral trial, Labor law.

\section{INTRODUCCIÓN}

La declaración de testigos en cualquier sistema procesal corresponde a una de las actividades más determinantes en la formación del juicio jurisdiccional. ${ }^{1}$ No obstante, su desarrollo dista de obtener una explicación simple, existiendo una dispersión manifiesta de criterios en su caracterización procesal.

CARnelutti, al describir la trascendencia de la prueba testimonial, la calificaba de "indispensable pero peligrosa", considerándola "un mal necesario". ${ }^{2}$ Alvarado Velloso, por su parte, nos alerta que lo que relate un testigo en un juicio, aun habiendo percibido y evocado el hecho correctamente, puede terminar exponiendo de forma errónea su contenido. ${ }^{3}$

${ }^{1}$ Dosi, Ettore, La Prueba testimonial. Estructura y funciones, Eds. Olejnik, Buenos Aires, 2016, p. 83.

${ }^{2}$ Carnelutti, Francesco, Cómo se Hace un Proceso, Editorial Temis, Buenos Aires, 2018, p. 102.

${ }^{3}$ Alvarado, Adolfo, La Prueba Judicial. Reflexiones Críticas sobre la Confirmación Procesal, Tirant Lo Blanch, Valencia, 2006, pp. 105-110; BALIC, Cristóbal, "Intervención del Juez Laboral en el interrogatorio de testigos: Iniciativa probatoria oficiosa y debido proceso", Revista Chile de Derecho del Trabajo y de la Seguridad Social, 2015, Vol. 6, № 11, pp. 107-132; "Un individuo, obrando de total buena fe, recuerda cosas no verdaderas. Lo que sucede en esta situación es que la persona no es consciente 
Contreras Rojas afirma que la obtención de una declaración testimonial libre de errores es la excepción, siendo muy probable que los testigos presenten aseveraciones incorrectas de los acontecimientos. ${ }^{4}$ Por lo que, aun desde distintas veredas en la concepción del proceso, se puede concordar $a b$ initio, que el interrogatorio de testigos transita en un campo de marcada "subjetividad". 5

Dicha particular característica hace que no sea indiferente lo que la norma procesal establezca para la práctica del mismo interrogatorio y las modalidades de pregunta que se permita realizar a los intervinientes, puesto que serán dichas reglas las que determinarán cómo un sistema procesal se adapte a las condiciones que mantiene esta prueba. Por ende, si dentro de la materia procesal laboral se desea ahora evaluar ciertos elementos de la declaración de testigos, corresponderá que se examine primero la regulación conforme a la cual se desarrolla.

Como observaremos, nuestro sistema procesal laboral, pese a estar sumido en una notoria oficialidad judicial, conserva determinados ámbitos adversariales en su regulación. ${ }^{6}$ Uno de dichos limitados espacios es la modalidad de rendición de la prueba testimonial. En efecto, el legislador no reguló la declaración bajo un sistema de confesión ante la judicatura o un sistema de "narración libre", donde el testigo depone de forma espontánea todo lo que conoce sobre el asunto materia de discusión. Por el contrario, optó por normar una rendición basada en la "técnica interrogativa", efectuada - por defecto y de forma preponderante- por los abogados de las partes bajo la dinámica de pregunta y objeción. Dicha opción legislativa por los interrogatorios directos, permite advertir inmediatamente dos puntos:

del hecho que su memoria, y los recuerdos relativos a un determinado suceso, han sido modificados $y$ distorsionados. (...) En otras palabras, al hecho de que no todos los testigos que mienten saben que mienten". MAzzon, Giuliana, ¿Se puede creer a un testigo? El testimonio y las trampas de la memoria, Editorial Trotta, Madrid, 2020, p. 17.

${ }^{4}$ Contreras, Cristián, La Valoración de la Prueba de Interrogatorio, Marcial Pons, Madrid, 2015, p. 147.

${ }^{5}$ Dosi, cit. (n. 1), p. 110; BaLIC, cit. (n. 3), p. 110; STÜRNER, Rolf, "La obtención de información probatoria en el proceso civil", Revista de Derecho Pontificia Universidad Católica de Valparaíso, 2008, Vol. 30, pp. 243-262; RúA, Gonzalo, Exámen Directo de Testigos, Ediciones Didot, Santiago, 2015, 3a edición, p. 23; Marinoni, Luiz G.; Cruz, Sergio, La prueba, Thomson Reuters, Santiago, 2015, p. 75.

${ }^{6}$ Palomo, Diego, "Segunda Parte: Procedimiento de Aplicación General”, en Delgado, J.; Córtez, G.; Palomo, D. (Eds.), Proceso Laboral, Thomson Reuters, Santiago, 2021, p. 173. 
(1) las preguntas que realicen los intervinientes para acreditar sus dichos corresponden a los instrumentos procesales con que contarán para hacer valer sus pretensiones a través de este medio de prueba, y (2) la forma en que sean enunciadas las preguntas o la decisión de qué artículos o verbos se utilizan, resultará determinante en el modo en que un sujeto declare sobre un determinado evento. ${ }^{7}$ En tal sentido, ningún interrogatorio será idéntico a otro, encontrándose cada uno afecto a una multiplicidad de factores en concreto.

Dentro de aquella innumerable cantidad de variables, se encuentra el incidente de parte o derecho litigioso, más trascendente en el desarrollo del interrogatorio: las objeciones que se presentan para detener la realización de preguntas. En efecto, su ejercicio en el desarrollo de una declaración testimonial, podría determinar la imposibilidad de ingreso de información inadmisible al pleito. En su interposición, el abogado litigante alerta al juez de un potencial error, llamándolo a excluir una pregunta del interviniente contrario y no considerar la línea de interrogación efectuada. ${ }^{8}$ Por lo mismo, se vuelve relevante conocer cuáles son sus fundamentos, o en específico, cuáles son los tipos de preguntas que habilitan la interposición de una objeción.

Al revisar la regulación que efectuó el Código del Trabajo, se puede advertir que no existe una referencia taxativa que responda de forma excluyente, cuáles son las causales de objeción que pueden invocarse a efectos de solicitar que sea inadmitida una pregunta. El artículo $454 \mathrm{~N}^{\circ} 6$, sólo prohíbe aquellas que contengan elementos de juicio que determinen la respuesta y las que refieran a hechos y circunstancias ajenas al objeto de la prueba. A partir de ello, cabe razonablemente preguntarse si éstos serían los únicos fundamentos que se podrían utilizar en una audiencia con el fin de objetar una pregunta.

De la revisión de lo expuesto por la doctrina, veremos que la mayoría de los pronunciamientos incluyen numerosos tipos de preguntas adicionales a las mencionadas indicando que también debieran ser inadmitidas. ${ }^{9}$ Ante

\footnotetext{
${ }^{7}$ Contreras, cit. (n. 4), p. 177.

${ }^{8}$ Vial, Pelayo, Técnicas y fundamentos en el contraexamen en el Proceso Penal Chileno, Librotecnia, Santiago, 2006, p. 249.

9 Palomo indica que las preguntas no admitidas en adición a la sugestivas serían las que sean "engañosas, confusas, impertinentes o repetitivas". PALOMO, cit. (n. 6), p. 118. Díaz establece una lista
} 
la existencia de diversos listados, se comienza a dificultar la posibilidad de establecer un compendio cerrado sobre los fundamentos legales que son admisibles para ejercer actualmente una objeción en una declaración testimonial laboral.

De esta forma, siendo públicos los registros de audio de numerosas audiencias de juicio laborales, corresponde que la labor académica implemente el "método de casos", cuyo sistema de análisis será útil a efectos de desentrañar el sentido y alcance de la inadmisión de preguntas en la praxis forense. ${ }^{10}$ Puesto que será sólo en el conocimiento práctico donde se hallará una caracterización efectiva sobre la interposición de objeciones en el desarrollo de exámenes y contrainterrogatorios. De esta forma, a través de la escucha de un número importante de declaraciones testimoniales, se buscará, entre otros propósitos, otorgar mayores evidencias sobre el contenido sustantivo de la facultad de objeción y verificar cuáles son las restricciones prácticas que frecuenta actualmente el interrogatorio de testigos en el proceso laboral.

\section{OBJECIÓN DE PREGUNTAS EN EL INTERROGATORIO}

\section{Descripción General}

En materia procesal, las objeciones han sido definidas como, las incidencias que tienen por objeto que el tribunal falle sobre la admisibilidad de una determinada información, evidencia o prueba, correspondiendo en específico, a la forma de oponerse a que se acepte una pregunta que contiene

aún más extensa al indicar: "b) Tipos de preguntas objetables: 1) Sugestivas, asertivas o inductivas. 2) Impertinentes. 3) Confusas. 4) De opinión o conclusivas. 5) Capciosas. 6) Coactivas. 7) Repetitivas. 8) Compuestas.". DíAz, Marcela, Manual de Procedimiento del Trabajo, Librotecnia, Santiago, 2018, $2^{\text {a }}$ edición actualizada, pp.147-148.

Raúl Fernández también añade preguntas a las mencionadas en la ley, indicando: "Se excluyen las preguntas de opinión, conclusivas, capciosas, compuestas, irrelevantes, destinadas a coaccionar ilegítimamente al testigo, asertivas y sugestivas (...)". Fernández, Raúl, La Prueba en el Proceso Laboral, Tirant Lo Blanch, Valencia, 2020, edición virtual, p. 693.

${ }^{10}$ Respecto del método de casos se expondrá con detenimiento más adelante. Álvarez, Magdalena; Rosseti, Andrés (coords.), Derecho a la Vida: Un análisis desde el método de casos, Ed. Advocatus, Córdoba, 2005, pp. 51-66. 
evidencia o información ilícita. ${ }^{11} \mathrm{Su}$ existencia supone un sistema procesal diverso a la modalidad de declaración testimonial libre, centrado en la posibilidad de desarrollar "técnicas interrogativas". ${ }^{12}$

En un modelo procesal adversarial clásico, corresponde sean interpuestas de forma verbal por los litigantes durante el curso de una declaración testimonial, oponiéndose oralmente a la pregunta efectuada por el litigante contrario. Quedando vedado el magistrado de interrumpir el interrogatorio de la parte, de no mediar una incidencia de objeción previamente interpuesta.

En contraposición a aquello, si se verifica su alcance en un sistema inquisitivo, es el mismo juez de plano que ordena el retiro de una pregunta que no cumpla con los requisitos referidos o bien instruye que ésta sea reformulada. En efecto, aún sin la forma de incidente de objeción propiamente tal, ante la sola detección de una pregunta inadmitida, el tribunal de oficio expresará los fundamentos de exclusión, debiendo el interrogador proceder a reformularla.

En este sentido, podemos afirmar que, manteniendo la naturaleza jurídica de un incidente, supone una mayor correspondencia de este instrumento procesal con un sistema adversarial, puesto que quién promueve la discusión de inadmisión de una pregunta, son las partes. El caso contrario de que el juez inadmita de plano una pregunta, correspondería al ejercicio puro de una facultad jurisdiccional.

En cuanto al objeto del presente incidente, se entiende debería dirigirse a la pregunta, no siendo propiamente objeción la que se dirige a la respuesta del testigo, aun cuando en la declaración se haya introducido información viciosa. La incidencia que podría efectuarse en ese caso, es más bien solicitar una reconvención sobre la actuación del testigo, puesto que la

\footnotetext{
${ }^{11}$ Vial, cit. (n. 8), p. 248; Sotelo, Cipriano, Práctica Forense del Contrainterrogatorio en el Juicio Oral, Editorial Flores, México D.F., 2015, pp. 90-91; de forma más simple Diego PALomo, en específico en materia procesal laboral, las define como: "Éstas son incidentes que se promueven en la audiencia y tienen como objeto impugnar una determinada pregunta realizada por el abogado de la contraparte". PALOMo, cit. (n. 6), p. 218: "La formulación oral de la disconformidad, alegando brevemente la razón jurídica en que se basa", e indicando que "El impugnante efectuará las alegaciones por las que la pregunta no deba ser admitida, esto es por incumplir alguno de los requisitos de admisibilidad". ABEL, Xavier; Picó, Joan, El Interrogatorio de Testigos, Bosch, Barcelona, 2008, Vol. 2, p. 318.

${ }^{12}$ Contreras, cit. (n. 4), p. 192.
} 
objeción sólo debiera dirigirse al acto jurídico interrogativo. ${ }^{13}$

Luego, debe ejecutarse por las partes en una oportunidad específica: inmediatamente concluida la pregunta del litigante contrario. Corresponde que se enuncie tras la realización de la pregunta y se exponga la objeción que corresponda. ${ }^{14}$ En caso contrario, de haberse producido la respuesta del testigo, el incidente debiera ser declarado extemporáneo.

Una vez formulada la objeción de parte, como todo incidente procesal en procedimiento oral, se entiende debiera darse traslado previo a la parte contraria (auditur et altera pars), a efectos de que el juez pueda resolver la incidencia invocada. Su locución verbal debe ser fundada, indicando el fundamento o norma infringida y los antecedentes de hecho que satisfacen la causal. Su resolución debe ejecutarse de forma inmediata por el juez en la audiencia. Antes de su resolución el abogado que efectuó la pregunta, puede allanarse reformulando en el mismo instante, evitando la resolución del tribunal.

Si el tribunal resuelve acoger la objeción, el abogado interrogante debe reformular la pregunta. Por su parte si el tribunal rechaza, el testigo debe proceder inmediatamente a contestarla. El deber judicial de pronunciarse sobre la admisibilidad de la pregunta irá conformando una "imagen previa" acerca del mérito probatorio de la declaración y de su idoneidad para la resolución del conflicto. ${ }^{15}$

2. Tratamiento normativo del Código del Trabajo sobre preguntas inadmitidas

Siguiendo a Gonzalo RúA, la mayoría de los sistemas procesales a nivel comparado han sido displicentes al momento de regular cómo se debe llevar a cabo la prueba testimonial. ${ }^{16}$ En este sentido, el Código del Trabajo al establecer este medio probatorio desarrolló diversos tópicos asociados a la declaración de testigos, no obstante, en cuanto a la forma y requisitos de las preguntas a formular en el interrogatorio, la referencia normativa

\footnotetext{
${ }^{13}$ Garrido, Carlos, Examen y Contraexamen de Testigos en el Proceso Penal, Editorial Metropolitana, Santiago, 2018, pp. 266-267.

${ }^{14}$ Lorenzo, Leticia, Manual de Litigación, Ediciones Didot, Buenos Aires, 2019, $7^{\text {a }}$ edición, p. 228.

${ }^{15}$ Contreras, cit. (n. 4), p. 86.

${ }^{16}$ RÚA, cit. (n. 5), p. 35.
} 
expresa resulta ser bastante escueta. ${ }^{17}$ Cuestión que no resulta extraña de la revisión comparada de la norma procesal; las legislaciones por regla general obvian cualquier disposición específica en este sentido o simplemente se conforman con indicar algunas cuestiones aisladas sobre cuáles preguntas se pueden realizar sin englobar muchas de las problemáticas que merecen consideración. ${ }^{18}$

Sin embargo, el derecho a interrogar testigos es un "derecho de configuración legal", lo que equivale a sostener que las partes deben someterse a las exigencias de la norma, por mínimas que sean, inclusive considerando la norma supletoria. ${ }^{19}$ De este modo, respecto de la forma de realizar interrogatorios, entramos a la necesidad de pronunciarnos sobre cuáles son los tipos de preguntas que pueden efectuarse en materia laboral.

En general, en un proceso se podrían efectuar preguntas narrativas, abiertas, cerradas no inductivas o afirmativas; no obstante, para definir, en concreto, qué preguntas se pueden hacer, habría que distinguir también el examen del contrainterrogatorio. ${ }^{20}$ Para ahondar en dichas consideraciones, se debe señalar que han existido variadas clasificaciones de preguntas en su tratamiento doctrinal, por lo mismo, la labor indagatoria deberá centrarse en las inadmitidas, en específico en el ámbito procesal laboral. ${ }^{21}$ El Código del Trabajo aun cuando establece preguntas inadmitidas similares a las que existen en sistemas comparados, no son técnicamente las mismas que se encuentran en otras áreas del sistema procesal chileno.

Redactada de forma escueta, el artículo $454 \mathrm{~N}^{\circ} 6$ extiende la limitación sólo a la formulación de preguntas de "forma asertiva", las que contengan "elementos de juicio que determinen la respuesta", y las que refieran a "hechos o circunstancias ajenas al objeto de la prueba". Como consecuencia

\footnotetext{
${ }^{17}$ Raúl Fernández estima que el medio de prueba regulado "con mayor detalle" en el Código del Trabajo, correspondería a la prueba testimonial. FERNÁNDEZ, cit. (n. 9), p. 672.

${ }^{18}$ Contreras, cit. (n. 4), p. 239.

${ }^{19}$ Contreras, Cristián, "Valoración de las pruebas de declaración de personas en segunda instancia" Tesis Doctoral, dirección del profesor Jordi Nieva Fenoll, Universidad de Barcelona, Barcelona, 2015, p. 40.

${ }^{20}$ Las preguntas abiertas caracterizan la labor del examen de los testigos, donde se intenta ahondar en diversos detalles que el testimonio espontaneo no ha especificado. "Las preguntas abiertas suelen empezar por: ¿Cuándo?, ¿Cómo?, ¿Dónde?, ¿De dónde?, ¿Hacia dónde?, ¿Desde cuándo?, ¿Por qué?, ¿A quién?, ¿Cuánto?, ¿Cuántas veces?”. García, Julio; Romero, Luis; González, Florentino, La Técnica del Interrogatorio, Editorial Rasche, Madrid, 2012, 3ª edición, p. 143.

${ }^{21}$ Contreras, cit. (n. 4), p. 177.
} 
de dicha regulación, no se admitirán por el juez de oficio ni a petición de parte, las preguntas que suponen que el testigo conoce la respuesta, cuando se la sugieren o se dirijan a establecer circunstancias fuera del juicio. Conforme a técnica legislativa expresa, aquellos serían los únicos fundamentos estrictamente legales para oponerse a una pregunta, y ante la no suficientemente explicada distinción entre la formulación asertiva y sugestiva, podríamos reconducirlos a solo dos motivos expresos: sugestión e impertinencia. ${ }^{22}$

Surge entonces la interrogante si aquellos serán los dos los únicos sustentos legalmente admisibles para oponerse a una pregunta en un interrogatorio laboral. Ante lo que cabe sostener que perfectamente las vías de fundamentación jurídica podrían alertar que la pregunta realizada infrinja elementos procesales de disposiciones análogas, en virtud de las cuáles se sustente el incidente de objeción.

La oposición fundada podría ser vinculada a una serie de normas anexas que efectúan pronunciamientos aplicables que pueden ser usados de forma argumentativa. Sin perjuicio de ello, no ha sido el legislador quién lo ha señalado expresamente, por cuanto corresponderá al juez, la determinación última del criterio de exclusión de la pregunta en concreto.

Por consiguiente, persiste la inexistencia de una respuesta clara para conocer cuáles son las preguntas que son inadmitidas en un interrogatorio laboral. No existiendo mayores respuestas expresas de la norma, será necesario ahondar en el conocimiento práctico de lo que ha sido ejercido en los procesos laborales.

\section{Aplicación del Método de Casos para el conocimiento de las objeciones}

A efectos de verificar cuáles han sido los fundamentos concretos de ejercicio de dicha facultad por sobre lo indicado en el artículo $454 \mathrm{~N}^{\circ} 6$, nos detendremos a continuación en el presente trabajo a efectuar análisis del interrogatorio laboral de modo práctico.

Siendo un incidente procesal el objeto del presente trabajo, para poder efectuar un desarrollo sustantivo del mismo deberemos involucrarnos

\footnotetext{
${ }^{22}$ La distinción entre asertiva y sugestiva fue explicitada mas no definida por el Código del Trabajo. Ver Infra. III. Características de la inadmisión de Preguntas en el Interrogatorio Laboral, 2.- Preguntas no admitidas, a) "Inductiva"/ "Sugestiva".
} 
con su práctica forense a efectos de obtener información del mismo. Para acercarnos a dicho conocimiento será relevante determinar la técnica jurídica a través de la cual efectuemos dicha labor y así, develar la visión global del contenido de las objeciones en el interrogatorio del proceso laboral. En virtud de dichas consideraciones, la metodología jurídica escogida fue el denominado "método de casos". ${ }^{23}$

A diferencia de una investigación clásica, cuyos objetivos generalmente implican la lectura de resoluciones judiciales que se vinculen con la temática ad-hoc, en este caso, dado los términos de desarrollo del incidente en estudio en el proceso laboral actual, sus registros de ejercicio sólo se hallan en archivos de audio. Los principios de oralidad y celeridad del proceso laboral, determinan que, a diferencia del proceso antiguo, el ejercicio de oposición a una pregunta en el desarrollo de interrogatorio sólo deje registro en audio. Lo que impide que su estudio se efectúe a través de una lectura jurisprudencial tradicional.

En virtud de dichas consideraciones, se estimó necesario efectuar un análisis de registros de audio de audiencia de juicio de Juzgados de Letras del Trabajo. La opción preponderantemente cuantitativa adoptada, exigía no sólo un análisis parcelado de determinados procesos cuyo aporte de conclusiones podría conducir a observaciones tendenciosas de respaldo a ideas preconcebidas. Por el contrario, debía definirse un "grupo de casos" que permitiese una dispersión estadística y amplitud en el conocimiento del ejercicio práctico.

Se definió realizar la escucha de 100 audiencias de juicio de causas seleccionadas de forma aleatoria con prueba testimonial rendida entre los años 2018, 2019 y 2020. ${ }^{24}$ Fue escogido el Primer Juzgado de Letras del

\footnotetext{
${ }^{23}$ El case method o método de casos es un sistema de investigación científica que, ha sido definido como el proceso didáctico que intenta la descripción, análisis e interpretación de un objeto de estudio concreto y singular en términos de calidad y complejidad; y que tiene como finalidad enseñar a elaborar una explicación científicamente argumentada del tema de estudio que sea coherente con el análisis general de la temática en la que se enmarca. LAIDA, Julia, "El Método del estudio de casos como estrategia metodológica para desarrollar habilidades investigativas en la formación del jurista", Iuris Tantum Revista Boliviana de Derecho, 2012, Vol. 13, pp. 60-101; URzÚA, Romina, Tutela Laboral: Análisis crítico desde el método de casos, Libromar, Santiago, 2017, p. 201; Pérez, Juan, "La Enseñanza del Derecho en Estados Unidos", Doxa (Universidad de Alicante), 1992, N¹2, p. 75.

${ }^{24}$ Durante el último trimestre del año 2020, fueron descargados desde la Oficina Judicial Virtual del Poder Judicial (https://oficinajudicialvirtual.pjud.cl/), los archivos de audio correspondientes a declaraciones testimoniales realizadas en audiencias de juicio, de 100 causas. Se utilizaron sólo archivos
} 
Trabajo de Santiago por mantener la mayor cantidad a nivel nacional de jueces en el periodo revisado, lo que supondría el conocimiento de una amplia variedad de criterios en la materia.

La escucha realizada durante finales del año 2020 y principios del año 2021, supuso la revisión de 277 declaraciones testimoniales en las que se encontraron presentes los abogados por ambas partes y el Juez de Letras del Trabajo. ${ }^{25}$ La extensión de dichas declaraciones sumadas las duraciones de las pistas de audio dieron lugar a la escucha de alrededor de 3.905 minutos de declaraciones. Conforme la revisión efectuada, se pasará a continuación a exponer lo constatado respecto del ejercicio del incidente de objeciones, cruzando los siguientes temas por describir: frecuencia, preguntas que son inadmitidas e intervención judicial oficiosa en la inadmisión.

\section{CARACTERÍSTICAS DE LA INADMISIÓN DE PREGUNTAS EN EL INTERROGATORIO LABORAL}

Concluida la escucha de las pistas y su análisis diagramado, corresponde realizar la descripción de lo observado desde diversas ópticas que resultarán útiles para la caracterización amplia del incidente de objeción. Corresponderá efectuar representación de cada uno de los elementos advertidos de las escuchas efectuadas, haciendo presente las consideraciones principales que pudieron ser constatadas:

\section{Frecuencia}

De la revisión del ejercicio práctico de objeciones por parte de los litigantes, cabe señalar que no corresponde a un incidente de comisión abundante en las declaraciones testimoniales observadas en el estudio de casos efectuado. Su presencia es menor a la que razonablemente se pudiera anticipar desde el estudio doctrinal respecto de una disputa de un juicio

que contenían declaraciones testimoniales en las cuáles hayan asistido abogados de ambas partes, a efectos de su idoneidad con el tema tratado. La individualización de las respectivas causas judiciales, con indicación del número de testimonios analizados en cada una, se indican en el Anexo del presente trabajo.

${ }^{25}$ Fueron descartados los audios de aquellas audiencias de juicio en que una de las partes se encontraba en rebeldía. 
adversarial laboral.

Fue detectada su presencia estadística en sólo 48 de las 100 audiencias de juicio que tuvieron declaraciones testimoniales. Totalizando 159 incidentes de objeciones interpuestos por las partes en 277 declaraciones testimoniales revisadas. Por lo que estadísticamente podría concluirse que, por cada dos declaraciones testimoniales íntegras, se presentó una sola objeción por las partes. ${ }^{26}$ Lo que supone un escenario testimonial de menor oposición e interrupción que el ejercicio litigioso podría suponer.

Tabla 1: Cantidad de objeciones en declaraciones testimoniales revisadas.

\begin{tabular}{|c|c|c|c|}
\hline $\begin{array}{c}\text { Cantidad de } \\
\text { declaraciones } \\
\text { testimoniales } \\
\text { revisadas }\end{array}$ & $\begin{array}{c}\text { Cantidad de declaraciones } \\
\text { testimoniales con } \\
\text { objeciones de parte }\end{array}$ & $\begin{array}{c}\text { Cantidad de } \\
\text { audiencias de juicio } \\
\text { con objeción de parte }\end{array}$ & $\begin{array}{c}\text { Cantidad de } \\
\text { audiencias de juicio } \\
\text { sin objeciones de parte }\end{array}$ \\
\hline 277 & 133 & 48 & 52 \\
\hline
\end{tabular}

Fuente: elaboración propia.

Al mérito del dato expuesto anteriormente, en 52 de 100 audiencias de juicio con declaración testimonial múltiple, simplemente no existió ejercicio de objeciones por ninguno de los intervinientes, totalizándose 144 declaraciones testimoniales libres de objeciones de parte. Dicha situación nos podría llevar a suponer que los interrogatorios fueron correctos y estrictamente apegados a la norma, no obstante, la experiencia profesional y escucha de dichas declaraciones testimoniales lleva a plantear la duda razonable si pudo existir una labor de oposición mayor a la realizada. Más aún, cuando por su parte, la inadmisión judicial de preguntas de oficio fue tan frecuente, cómo veremos más adelante.

\section{2.- Preguntas no admitidas.}

En el análisis central de la presente monografía, cabe señalar que, de

\footnotetext{
${ }^{26} \mathrm{Si}$ deseamos profundizar en la estadística podemos verificar la cantidad de objeciones por minutos de declaración, siendo 159 las objeciones interpuestas por las partes en 3905 minutos. Se podría concluir que cada 24 minutos y medio de declaración testimonial una de las partes objeta la pregunta del interrogante contrario.
} 
las escuchas efectuadas, pudieron verificarse seis enunciaciones distintas con que se calificaron las preguntas que solicitaban fueran inadmitidas, tanto en exámenes como en contrainterrogatorios laborales. ${ }^{27}$ En este sentido, las preguntas fueron inadmitidas por ser calificadas textualmente con la denominación de "inductiva/sugestiva", "impertinente", "inadmisible" "confusa", "coercitiva" o "reiterativa".

Tabla 2: Cantidad de objeciones tipo de pregunta. Porcentajes totales.

\begin{tabular}{|c|c|c|}
\hline Pregunta Inadmitida & Cantidad de Objeciones & Porcentaje \\
\hline Inductiva & 77 & $48,4 \%$ \\
\hline Impertinente & 31 & $19,5 \%$ \\
\hline Inadmisible & 15 & $9,4 \%$ \\
\hline Confusa & 19 & $11,9 \%$ \\
\hline Reiterativa & 14 & $8,8 \%$ \\
\hline Coactiva & 3 & $1.9 \%$ \\
\hline
\end{tabular}

Fuente: elaboración propia.

a) "Inductiva" / "Sugestiva"

Corresponde al fundamento más frecuente para la exclusión de una pregunta en un juicio laboral. Conforme la revisión efectuada, la locución de incidentes por pregunta inductiva/sugestiva corresponden al 48,5\% del total de solicitudes de inadmisión interrogativas en las declaraciones testimoniales laborales. En este sentido, cabe señalar que en el uso práctico observado no se distinguió entre el concepto preguntas sugestiva y asertiva, pese a que doctrinalmente referirían a una situación sutilmente distinta.

Por pregunta sugestiva / inductiva se ha entendido que son aquellas que "contienen su propia respuesta", aportando la información que se desea obtener con la interrogación. ${ }^{28}$ En cambio, por pregunta asertiva, son aquellas que fueron efectuadas del modo que quién la realiza, sabe la respuesta, por lo que la pregunta podría transformarse en un "vehículo para hacer llegar al testigo información". ${ }^{29}$ Sin perjuicio de aquello, esta sutil

\footnotetext{
${ }^{27}$ Se consideraron las enunciaciones que al menos se repitieron una vez en la revisión realizada.

${ }^{28}$ Decap, Mauricio, La Prueba de los Hechos en el Proceso Penal, Libromar, Santiago, 2019, T. I, pp. 51-57.

${ }^{29}$ Fernández, cit. (n. 9) p. 692.
} 
distinción no fue aplicada en ninguno de los pronunciamientos judiciales revisados que resolvieron los incidentes de objeción, siendo denominada por los intervinientes de forma unánime como "inductiva" o "sugestiva". Por consiguiente, su identificación general simplemente corresponderá a una pregunta cerrada que sugiere una determinada forma de realización otorgando solo la posibilidad de un sí o no por respuesta. ${ }^{30}$

Normativamente es una pregunta inadmitida de forma expresa por el Código del Trabajo, extendiendo el legislador un amplio mandato de exclusión al respecto. El artículo $454 \mathrm{~N}^{\circ} 6$ del Código del Trabajo en su inciso $2^{\circ}$ afirma que las preguntas a efectuar no podrán "formularse en forma asertiva”. Sin embargo, el mandato es tan categórico que olvida distinguir entre el examen y contraexamen, pudiendo llevar a confusiones.

En efecto, se puede verificar que el artículo $454 \mathrm{~N}^{\circ} 6$ no indicó expresamente que sólo se encuentren vedadas en el examen, lo que en principio también abarcaría la prohibición al contraexamen. Sin embargo, dicha interpretación corresponde a todas luces a un error que contravendría las bases del mecanismo de juicio contradictorio e impediría un ejercicio correcto de la labor litigiosa adversarial ante un testigo de la contraparte. ${ }^{31}$ Un sistema que no admita en el contraexamen la admisión de preguntas sugestivas que permitan confrontar la información vertida, no correspondería a un modelo "destinado a la producción de información de alta calidad". ${ }^{32}$ Exhibir y extraer de los testigos aquellas porciones del relato que no han sido presentados en el examen directo, a través de un estilo asertivo, es el instrumento por excelencia del contraexaminador. Por consiguiente, se estima que la norma sólo refiere al examen, no pudiendo fundarse objeción en esta causal en el desarrollo de un contrainterrogatorio.

Sin perjuicio de ello, cuando la respuesta a la pregunta no admite más que una sola formulación de la realidad, la sugestión podría ser admitida, tales como las preguntas sugestivas "introductorias", de "acreditación" o de "transición".33

\footnotetext{
${ }^{30}$ Garrido, cit. (n. 13), p. 249; Contreras, cit. (n. 4), p. 177.

${ }^{31}$ Fernández, Óscar, Máximas del Interrogatorio, Thomson Reuters - Aranzadi, Navarra, 2019, p. 23.

${ }^{32}$ RÚA, cit. (n. 5), p. 27.

${ }^{33}$ Couture, Eduardo, Los Mandamientos del Abogado, Ed. Coyoacán, México D.F., 2013, p. 26; RúA, cit. (n. 5), p. 95.
} 


\section{b) "Impertinencia"}

Corresponde al fundamento más sustantivo para la exclusión de una pregunta en juicio, y consiste en aquella interrogante que se aparta de la controversia fáctica del pleito, al no evidenciar conexión con los hechos pertinentes sustanciales y controvertidos fijados en audiencia preparatoria. Según la revisión efectuada, se trata del segundo tipo de pregunta más incidentada por los litigantes $(19,5 \%)$.

Se basa expresamente en el reseñado artículo $454 \mathrm{~N}^{\circ} 6$ del Código del Trabajo, que señala "el tribunal y las partes podrán formular a los testigos las preguntas que estimen necesarias para el esclarecimiento de los hechos sobre los que versa el juicio" y luego, indica en su segundo inciso que no podrán referirse a "circunstancias ajenas al objeto de la prueba". La referencia de denominación al vocablo "impertinencia" proviene del numeral $\mathrm{N}^{\circ} 4$ del mismo artículo 454 , referida a la prueba de absolución de posiciones, en las que se exige que las preguntas a efectuar al absolvente, deberán ser "pertinentes" a los hechos de prueba.

En mérito de lo expuesto, la inadmisión a las preguntas impertinentes mantiene un fundamento que sostiene una vinculación normativa demostrable y con menor margen para la discrecionalidad. Esto pues, teóricamente, su discusión jurídica antecede al interrogatorio, sentando sus bases en la discusión de los puntos de prueba. Conforme lo observado, son objeto de esta incidencia aquellas preguntas que respondían a temáticas ajenas al thema decidendi, como también aquellas que referían a hechos no controvertidos.

Una técnica retórica frecuente en la incidencia de objeción ante una pregunta impertinente, es la demostración causal que aún de acreditarse el hecho que supone la pregunta, no se conduciría de forma alguna a acoger o rechazar la acción de fondo incoada. Por su parte, como argumento de oposición, usualmente se esgrime la técnica indiciaria, indicando que el hecho sobre el que se interroga motivaría la aplicación de un punto de derecho relacionado. ${ }^{34}$ Aplicación que resulta razonable, siendo plausible que una determinada línea de preguntas no exhiba su propósito sino hasta el

${ }^{34}$ La técnica indiciaria mantiene un uso frecuente en el derecho procesal laboral. Cfr. BRONSTEIN, Arturo, La Subordinación o Dependencia en el Contrato de Trabajo, Lexis Nexis, Santiago, 2005, p. 235. Marinoni y Cruz, cit. (n. 5), p. 103. En cita a Stein, Friedrich, El Conocimiento Privado del Juez, traducción de Andrés de la Oliva Santos, Editorial Universitaria Ramón Areces, Madrid, 1990, pp. 30-31. 
término de la interrogación. ${ }^{35}$ Luego, mientras sea plausible estimar que se interroga sobre un hecho jurídicamente relevante, o a su vez que manifiesta coherencia con el resto de los elementos de prueba ofrecidos en la causa, se entiende se cumpliría con el mandato normativo. ${ }^{36}$

La aplicación más estricta de este criterio, podría llevar a pensar en la exclusión de las denominadas "preguntas de acreditación", por no mantener relación con el asunto debatido en el juicio. ${ }^{37}$ Las preguntas que versan sobre la denominada preambula fidei, son aquellas que están destinadas a "aquilatar la capacidad del testigo de percibir y narrar especialmente en lo que a su credibilidad se refiere". ${ }^{38}$ En razón de la eliminación del antiguo incidente civil de tachas, se comprende que, por su ausencia en el ámbito laboral, resulte necesario conceder a la parte que interroga, el derecho a efectuar preguntas tendientes a demostrar la credibilidad del testigo, la existencia de vínculos con alguna de las partes que afectaren o pudieren afectar su imparcialidad, o en general, defectos de idoneidad en el estándar probatorio que eventualmente se le asigne a su declaración. ${ }^{39}$

\section{c) "Inadmisible"}

Según la revisión efectuada, se trata del tercer tipo de pregunta más incidentada por los litigantes $(9,4 \%)$. La denominada "objeción por inadmisible", por regla general, refiere a la imposibilidad de extenderse el interrogatorio a opiniones del testigo. Corresponde a la pregunta que pierde la característica de apuntar a una dimensión propiamente fáctica, para solicitar al testigo que revele su parecer sobre un punto técnico o de derecho. ${ }^{40}$

\footnotetext{
${ }^{35}$ Contreras, cit. (n. 19), p. 40.

${ }^{36}$ Según TARUFFo, un hecho es jurídicamente relevante, cuando corresponde al supuesto de hecho definido por una norma jurídica que se considera posiblemente aplicable al caso. TARUFFo, Michele, Simplemente la verdad: El Juez y la Construcción de los Hechos, Marcial Pons, Madrid, 2010, p. 55; Contreras, cit. (n. 4), p. 43.

${ }^{37}$ Palomo, cit. (n. 11), p. 216.

${ }^{38}$ Dosi, cit. (n. 1), pp. 98-99.

${ }^{39}$ No rigen en el proceso laboral dichos motivos expuestos en el artículo 357 y 358 del Código de Procedimiento Civil. Contreras, cit. (n. 19), p. 222, en cita a: Silva Melero, V., "La prueba procesal", Revista de Derecho Privado, Madrid, 1963; Cfr. Retamales, Romina, "Herramientas tecnológicas en la prueba testimonial en la Reforma Procesal Civil", Memoria para optar al grado de Licenciado en Ciencias Jurídicas y Sociales, dirigida por la Profesora Lorena Donoso, Universidad de Chile, Santiago, 2017, p. 91.

${ }^{40}$ TARUFFo indica que los enunciados jurídicos forman parte de las certidumbres del juez, mientras que
} 
Enseguida se debe determinar dónde se encuentra su fuente normativa. Al respecto se debe indicar que no se establece una prohibición expresa en el Código del Trabajo. El artículo $454 \mathrm{~N}^{\circ} 6$, específicamente en su inciso $1^{\circ}$, sólo efectúa la prevención que debe estar dirigida al "esclarecimiento de los hechos del juicio", no efectuando una limitación categórica respecto del tenor fáctico de la misma. Asimismo, para subrayar su lineamiento con el objeto de la prueba, habla de "hechos o circunstancias", por lo que cabe hacer presente que el Código ni siquiera ha subrayado la referencia a la palabra "hechos" como elemento exclusivo del acto interrogativo.

Luego, los fundamentos de esta objeción tampoco logran identificarse de inmediato en las bases procesales civiles que definen el rol de un testigo en un juicio. El artículo 367 del Código de Procedimiento Civil indica que los testigos deben responder "expresando la causa por qué afirman los hechos aseverados". Lo que nuevamente no es concluyente respecto de que exista efectivamente una limitación sobre las preguntas que llamen al testigo a hipotetizar.

En principio, se concuerda que lo que suponga o especule el testigo no logra ser relevante para la resolución de un conflicto jurídico, no debiendo incorporarse al juicio dicha información. ${ }^{41}$ Se entiende que las conclusiones sobre cualquier circunstancia requerirían la opinión de un experto, buscando una deducción cuyo rol no le permite efectuarla. Puesto que su función es declarar sobre "hechos" no sobre materia de pronunciamiento jurídico. ${ }^{42}$

Dicho análisis es funcional a sostener la prohibición de preguntas sobre puntos de derecho; pudiéndose concordar que no se debería conducir un testimonio en ahondar en las convicciones jurídicas que mantenga el testigo. ${ }^{43}$ Sin perjuicio de ello, la situación se volverá ciertamente más

las afirmaciones de hecho tienen el status epistémico de incertidumbres. Cfr. TARUFFO, cit. (n. 36), p. 29; Sotelo, cit. (n. 11), p. 94; Alcaíno, Rodrigo; Cortés, Matías, Curso Elemental de Litigación Oral, Editorial Jurídica de Chile, Santiago, 2020, p. 214; no debe confundirse esta clasificación con aquella pregunta que solicita una opinión de derecho al testigo el que podría desconocer el significado de determinado concepto jurídico, y es debido a ello que no la comprende. En contraste con la presente clasificación en la cual nos referimos al caso en que el tema técnico sí es conocido por el testigo. García, Romero y GonZÁlez, cit. (n. 20), p. 151.

${ }^{41}$ FernándeZ, cit. (n. 31), p. 47.

${ }^{42}$ Ferrater, José, Diccionario de Filosofía Abreviado, Editorial Sudamericana, Buenos Aires, 1975, p. 163; En este sentido, parece ser razonable la distinción de hechos presentada por Mauricio Decap, que divide entre hecho externo, percibido, interpretado y narrado. DeCAP, cit. (n. 28), pp. 51-57.

${ }^{43}$ TARuffo, cit. (n. 36), p. 53. 
confusa en cuanto a la prohibición del acto interrogativo respecto de puntos técnicos.

Al respecto, cabe señalar que el fundamento normativo para ello, se encontraría en el contrapunto con la prueba pericial. ${ }^{44}$ Las preguntas con un carácter técnico, se encontrarían en el ámbito de declaración de los peritos que, conforme lo señalado por el artículo 409 del Código de Procedimiento Civil, se les consultan "opiniones". El perito declara respecto del punto consultado por el tribunal en base a sus conocimientos especiales de alguna ciencia o arte. En este sentido, sus deducciones son relevantes porque se alinean precisamente con el objeto procesal de su labor como auxiliar de la administración de justicia.

Como respuesta a ello, surge la figura del "testigo experto", como un intermedio entre ambos tipos de declaraciones. ${ }^{45}$ Se ha indicado por doctrina que esta figura, no estaría permitida en materia laboral, precisamente en base a la inadmisibilidad de preguntas ajenas a los hechos de conocimiento del testigo. ${ }^{46}$ En este punto, se debe hacer presente que la calificación de "testigo experto" se presenta como una categoría doctrinal, no existiendo procesalmente una calificación ex ante de los testigos en audiencia preparatoria. Este escenario determina que no exista ninguna denominación que anteceda a su declaración, debiendo controlarse precisamente a través del instrumento de objeciones de inadmisibilidad. No obstante, cuando nos adentremos en las convicciones de un testigo, no serán tan sencillas de delimitar.

Dentro de los fundamentos para prohibir la pregunta sobre temáticas que no serían propiamente hechos, es que el testigo no se hallaría capacitado para dar una respuesta eficaz. ${ }^{47}$ Cabría cuestionarse entonces qué sucede con este fundamento, cuando sí es posible que el testigo comunique al tribunal ciertos conocimientos.

En este sentido, sólo un intenso control sobre la técnica interrogativa

\footnotetext{
44 "Las preguntas no pueden referirse a los juicios de valor del testigo sobre los hechos que conoce ni a sus apreciaciones conclusivas. Aquí está la diferencia con el perito que aporta máximas de la experiencia y conocimiento técnico". Fernández, cit. (n. 9), p. 691.

${ }^{45}$ En legislaciones comparadas tales como la española, se encuentra regulada la figura del testigo experto o testigo perito. Fernández, Oscar, Arte y Técnica del Interrogatorio, Thomson Reuters - Aranzadi, Navarra, 2017, p. 30.

${ }^{46}$ FernándeZ, cit. (n. 9), pp. 540-541.

${ }^{47}$ Sotelo, cit. (p. 18), p. 95.
} 
que objete la inadmisibilidad, podría detener el tránsito teórico de una declaración testimonial a la figura descrita. Lo que será inmediatamente estéril, si el testigo habla desde un conocimiento técnico, en tanto, su misma retórica lo condujo a pronunciarse espontáneamente de dicha forma. $\mathrm{Al}$ respecto, la psicología del testimonio nos enseña que los conocimientos juegan un rol determinante en lo que cada sujeto observa; lo que ven los testigos no depende sólo de los elementos presentes en la escena, sino también de sus convicciones precedentes. ${ }^{48}$ En efecto, los testigos declaran desde un "saber preconstituido", cuyo interrogatorio puede develarlo, a través de una serie de preguntas admisibles. ${ }^{49-50}$ Dicho conocimiento no es estrictamente una opinión técnica, puesto que el testimonio sólo aporta un determinado hecho desde su subjetividad y relatividad que deberán ser valorados por el juzgador en su sentencia. ${ }^{51}$

En definitiva, se entiende que el encasillamiento fáctico del artículo 454 no se comprende se dirija a una censura al pronunciamiento del testigo sobre una determinada temática que le atañe personalmente. La resolución sobre si es fáctica la pregunta, abre un campo difuso de delimitación que aconseja un ejercicio menos restrictivo de la potestad jurisdiccional de limitar preguntas en este punto.

\section{d) "Confusas"}

La denominación de objeción por "confusa" como fundamento de la inadmisibilidad corresponde a una situación procesal de relativa frecuencia conforme lo observado en la investigación efectuada (11,9\%). Su incidencia se dirige a las preguntas que, por la forma que fueron elaboradas, contienen información que podría inducir a que la respuesta aportase información en términos engañosos. Son preguntas que inducen al error del testigo porque contienen información potencialmente equivocada, que presentan como si fuera verdadera. ${ }^{52}$

\footnotetext{
${ }^{48}$ Mazzoni, cit. (n. 3) p. 41.

${ }^{49}$ FernándeZ, cit. (n. 45), p. 24.

${ }^{50}$ Dosi, cit. (n. 1), p. 25.

${ }^{51}$ Quizás uno de los puntos que nos llevará a distinguir la opinión técnica del perito en su declaración con la propiamente testimonial, es la obligación del testigo de expresarse en un lenguaje normalmente usado en la narración de la relación de los hechos. Dosi, cit. (n. 1), pp. 34 y 37.
}

${ }^{52}$ Mazzoni, cit. (n. 3), p. 82. 
Puede observarse su comisión más usual en el contraexamen, donde el abogado que interroga frecuentemente busca que el testigo incurra en ciertas trampas lingüísticas. Esta categoría mantiene una similitud parcial con la pregunta sugestiva, cuya identificación ha sido particularizada como aquellas que contienen largas introducciones, que suelen confundir al testigo y hacen finalmente perder el objetivo del interrogatorio. ${ }^{53}$

La vinculación normativa de este tipo de pregunta es bajísima, no existiendo mención expresa al impedimento sobre interrogar un testigo de forma confusa. Sólo por analogía correspondería situar su fundamento en el artículo $454 \mathrm{~N}^{\circ} 4$ del Código del Trabajo, que, de forma expresa para la declaración de las partes en la diligencia de absolución de posiciones, exige que se efectúen en términos "claro y precisos". Luego, en términos más difusos, también en el mismo artículo $454 \mathrm{~N}^{\circ} 6$, se indica que las preguntas no podrán "contener elementos de juicio que determinen la respuesta", lo que finalmente la podría asimilar a una categoría de pregunta sugestiva/ inductiva.

Pudo verificarse que en varias objeciones fue vinculado discursivamente al principio de buena fe. Dicha fundamentación arrastra la serie de críticas de las eventuales arbitrariedades que podrían efectuarse en la resolución jurisdiccional de incidencias basadas exclusivamente en un "concepto jurídico indeterminado". ${ }^{54}$ En otras palabras, no corresponde que una inadmisión de preguntas se funde en un concepto ambiguo, que puede ser usado para explicar casi todo, lo que lo vuelve pernicioso conforme al debido proceso y heurístico en lo argumentativo..$^{55}$

Un subconjunto de este tipo de preguntas son las que la doctrina ha denominado "conclusivas" o "argumentativas". ${ }^{56}$ No obstante, no ser

${ }_{53}$ DíAz, cit. (n. 9) p. 148; La doctrina comparada las define también como "capciosas". GARCíA, Romero y Gonź́lez, cit. (n. 20), p. 155. En el mismo sentido, también se encuentran las denominadas "compuestas". "Las preguntas compuestas no son admisibles porque contienen más de dos hechos. (...) Aqui lo recomendable es formular dos preguntas por separado". Sotelo, cit. (p. 18), p. 84.

${ }^{54}$ Palavecino, Claudio; Ruay, Francisco, "El principio de la buena fe en los procedimientos laborales frente al principio de legalidad o juridicidad. ¿Tienen los jueces del trabajo facultades tácitas o implícitas?", en: Palomo, D. (Dir.), Proceso y Justicia Laboral: Lecturas a Contracorriente, Ediciones Jurídicas de Santiago, Santiago, 2015, pp. 431-464; RuAY, Francisco, Las Potestades Atípicas del Juez Laboral: Una lectura crítica, Ediciones Jurídicas de Santiago, Santiago, 2017, p. 121.

${ }^{55}$ Contreras, cit. (n. 4), p. 119.

${ }^{56}$ Dentro de esta referencia pueden igualmente incluirse las denominadas "preguntas argumentativas", las cuales no buscan necesariamente una respuesta, sino que señalan una conclusión y solicitan o no, 
referidas con dicho rótulo en la revisión del "grupo de casos", pueden perfectamente encasillarse en esta categoría y comparten el mismo déficit de señalamiento normativo que reconozca su prohibición expresa. Éstas corresponden al abogado que, al preguntar, expone una conclusión que pudiera no desprenderse de lo que ha señalado el testigo o podría corresponder a una interpretación que debiera comunicarse en las observaciones a la prueba. En definitiva, el error se encuentra en que el testigo está para acreditar los hechos y no para homologar las conclusiones a las que arribe el interrogador. ${ }^{57}$ Mantiene el lineamiento en lo confuso, puesto que podría llevar a una contradicción con lo declarado por el testigo.

Las resoluciones de los tribunales que acogen este tipo de objeciones, sostienen que la respuesta podría conllevar a una conclusión equivocada, puesto que supone una situación no equivalente al conflicto de autos o porque parte de una base de una declaración parafraseada de manera incorrecta.

\section{e) "Reiterativa"}

Conforme a las escuchas efectuadas, la denominación "reiterativa" fue empleada por los intervinientes para oponerse a preguntas que en su concepto habían sido anteriormente formuladas y contestadas por el testigo $(8,8 \%)$. Se trata del tipo de incidencia que más responde a la dinámica procesal del interrogatorio, por lo que su admisión quedará estrictamente sometida a las circunstancias del mismo. De esta forma, los litigantes por la vía del incidente de objeción, enuncian al tribunal la oportunidad anterior que se había realizado.

De la misma forma que el tipo anterior de objeción, no tiene reconocimiento expreso más que en la facultad del tribunal contenida en el artículo 430 del Código del Trabajo, que indica que deberán adoptar "medidas necesarias" para impedir las "actuaciones dilatorias". Por lo que, no existiendo pronunciamiento expreso respecto de la reiteración, correspondería argumentar en derecho estricto por la repetición de la pregunta exclusivamente cuando incurriese en una dilación manifiesta. ${ }^{58}$ De esta forma, corresponde que se haga un ejercicio restrictivo de dicha

al testigo concordar con ellas.

${ }^{57}$ García, Romero y GonzÁlez, cit. (n. 20), p. 95.

${ }^{58}$ Francisco Ruay advierte respecto de la invocación judicial de facultades a partir del apelativo "medidas necesarias". RuAY, cit. (n. 54), p. 117. 
calificación en aras de resguardar la garantía del debido proceso, puesto que no existe una limitación temporal al desarrollo de un testimonio. No obstante, el litigante deberá asumir que la prolongación excesiva de su duración, conspira con la atención que se desea obtener. ${ }^{59}$

Se ha insistido en su tratamiento práctico, que debe tratarse de una pregunta ya contestada, abriendo la discusión sobre si la respuesta anterior fue conclusiva de su conocimiento sobre el hecho o podría constituir una respuesta evasiva.$^{60}$ Por lo mismo, si una pregunta no ha sido contestada de forma suficiente por el testigo, no correspondería se inadmitiera la pregunta por esta causa.

Conforme al uso observado, cabe señalar que en ocasiones se utilizó la denominación "sobreabundante", cuando se había entendido que el testigo había ahondado de forma suficiente en la temática sobre la que se le pregunta. ${ }^{61}$ En este sentido, se ha hablado en doctrina sobre un eventual "punto de saturación", que se genera cuando la cantidad de preguntas en una determinada línea excede la necesaria para lograr la convicción, no aportando información nueva para el esclarecimiento de los sucesos. ${ }^{62}$ No existe reconocimiento a dicha hipótesis, más allá de la facultad jurisdiccional de exclusión ex ante del número de testigos por "constituir inútil reiteración sobre hechos suficientemente esclarecidos".

\section{f) "Coercitiva"}

Corresponde a la denominación más escasa hallada en la revisión de casos (1,9\%). La interposición de incidencia por "coactiva" o "coercitiva", refiere a aquellas preguntas que hostilizan o determinan una presión abusiva sobre el testigo. Corresponde a una forma de interrogación, que, a través del lenguaje verbal o no verbal, se presiona al interrogado, comprometiendo su

\footnotetext{
${ }^{59}$ Contreras, cit. (n. 19), p. 69-70. En cita a Nieva, Jordi, "Los problemas de la Oralidad", Justicia Revista de Derecho Procesal, 2007, Número 1-2, pp.101-130. Por cierta parte de la doctrina es considerada dentro de las denominadas preguntas "confusas", puesto que preguntar muchas veces precede al error, al intentar que el testigo se contradiga respecto de un punto sobre el cual ya expuso en su declaración. Ortega, Waldo, Litigación Oral para el Proceso Penal, Ed. Universidad Católica de la Santísima Concepción, Santiago, 2012, pp. 200- 204.

${ }^{60}$ Cfr. Baytelman, Andrés; Duce, Mauricio, Litigación Penal. Juicio Oral y Prueba, Grupo Editorial Ibáñez, Bogotá, 2014, p. 201.

${ }^{61}$ García, Romero y González, cit. (n. 20), p. 195.

${ }^{62}$ Contreras, cit. (n. 4), p. 45.
} 
libertad para formular respuestas. ${ }^{63}$

Su vinculación normativa en el Código del Trabajo es casi inexistente, no obstante, la presente investigación demuestra su ejercicio en la práctica forense laboral. Cabe tener en consideración que los testigos declaran bajo juramento o promesa de decir la verdad so pena de incurrir en el delito de falso testimonio de conformidad al artículo 209 del Código Penal. Por lo que se entiende suficiente dicho apercibimiento que se efectúa de forma previa al interrogatorio, de acuerdo al artículo 363 del Código de Procedimiento Civil, y no correspondería que las preguntas de un abogado se enuncien ligándose a la persecución penal.

El único fundamento propiamente laboral, sería el referido artículo 430 del Código del Trabajo, sobre facultades oficiosas, que indica que los tribunales deberán adoptar "medidas necesarias" para impedir el fraude, colusión y abuso del derecho. ${ }^{64}$ Luego, no siendo claro que el legislador haya puesto un límite expreso a la comisión de preguntas denominadas "coactivas" corresponde nuevamente interpretar dicha facultad de manera estricta. De esta forma, se evita extender el campo de la discrecionalidad de las potestades jurisdiccionales en el proceso laboral cuya oficialidad aparece suficientemente subrayada.

En virtud de lo señalado, se estima que su aplicación debiera quedar asociada a las preguntas que por la forma en que fueron efectuadas impiden que se respondan con la libertad que merece un interviniente en juicio. En efecto, en el desarrollo de los interrogatorios de contraexamen es usual verificar una hostilidad natural, cuya base supone, algunas veces, la "incomodidad lingüística" del testigo. ${ }^{65}$ Sin perjuicio de ello, conforme a las reglas de comportamiento más básicas que se puedan concordar de un proceso judicial, no puede ejercerse un estilo de interrogación donde el abogado ironice de los dichos del testigo; no sólo por mantener esta cuestionable denominación de "coercitiva", sino porque se aparta del esquema de estructura de pregunta y respuesta. ${ }^{66}$ Redundando muchas veces en la categoría de inadmisión anterior,

\footnotetext{
63 “¿No se da cuenta que mentir en juicio está penado con la cárcel?”. FERnÁndEZ, cit. (n. 31), p. 82.

${ }^{64}$ Palavecino, Claudio, "La Reforma Procesal Laboral Chilena: Una visión crítica desde el Garantismo Procesal", Revista Laboral Chilena, 2012, № 208, pp. 59-68; PALOMo, Diego (Dir.), Proceso y Justicia Laboral: Lecturas a Contracorriente, Editorial Jurídica de Santiago, 2015, Tomo I, pp. 151-176.

${ }^{65}$ Micheletti, Pablo, Litigación oral desde el lenguaje corporal, Editorial Librería Cívica, Santa Fe, 2019, p. 123.

${ }^{66}$ Alcaíno y Cortés, cit. (n. 40), p. 214.
} 
como una pregunta "confusa", no interesando en esta oportunidad procesal la opinión del abogado.

Finalmente, cabe señalar que doctrinalmente se ha incluido dentro de los fundamentos de preguntas inadmitidas aquellas que pudieran autoincriminar al testigo en algún delito. De la revisión de casos no pudo ser detectada ninguna objeción fundada en este término. Aun así, teóricamente es difícil advertir su posibilidad más allá de lo que podría ser calificado como una pregunta coactiva o coercitiva.

En el inciso $3^{\circ}$ del artículo $453 \mathrm{~N}^{\circ} 4$, se indica que "no podrán ser apreciadas por el tribunal las pruebas aporten y que se hubieren obtenido directa o indirectamente por medios ilícitos o a través de actos que impliquen violación de derechos fundamentales". Esta norma podría eventualmente ser aplicada en el sentido de negar la posibilidad de producir convicción al interrogatorio que ha obtenido respuestas de forma ilícita o con violación de derechos fundamentales. ${ }^{67}$ En este caso, la ejecución de este tipo de preguntas correspondería a una forma de producción de prueba ilícita, puesto que la coacción es contemporánea a la rendición de la prueba, siendo distinta a la situación en que el testigo eventualmente haya obtenido su conocimiento de manera indebida. ${ }^{68}$

\section{3.- Iniciativa judicial de la objeción.}

El Código de Procedimiento Civil establece que son las partes quiénes ejercen propiamente el incidente "sobre la conducencia de las preguntas", correspondiendo al tribunal sólo resolver. Sin embargo, en el procedimiento laboral será necesario hacer ciertas precisiones. El Juez de Letras del Trabajo, como director del proceso, preside la audiencia, dirige el interrogatorio y califica la procedencia de las preguntas que se dirigen al testigo. ${ }^{69}$ Con un marcado reforzamiento de las potestades judiciales, surge de inmediato el cuestionamiento si sus atribuciones contienen la facultad de calificar de oficio la procedencia de preguntas en el interrogatorio, o bien, su resolución debe

\footnotetext{
${ }^{67}$ Alcaíno y Cortés, cit. (n. 40), p. 214.

${ }^{68}$ Marinoni y Cruz, cit. (n. 5), p. 56.

69 "Esta calificación la hace el juez sin más trámite (...)", "Se le ha atribuido al juez el papel director del mismo". Academia Judicial, Manual de Juicio del Trabajo, Academia Judicial, Santiago, 2017, $2^{\text {a }}$ edición, p. 40; FERNÁNDEZ, cit. (n. 9), p. 672.
} 
darse sólo tras la solicitud de una parte. ${ }^{70}$

De la atenta lectura de la norma positiva, se afirmará que dicha facultad de calificación previa de preguntas no presenta un fundamento normativo expreso y sólo podría tener sustento en los mandatos generales de los artículos 429 y 430 del Código del Trabajo. ${ }^{71}$ Ahora bien, el Manual de Juicio del Trabajo con que la Academia Judicial instruye a la judicatura laboral, reconoce de forma expresa esta facultad de calificación previa de preguntas, para indicar sólo como segunda hipótesis, que el Juez debe pronunciarse "además, cuando una de las partes objeta la que formule la parte contraria". ${ }^{72}$

En efecto, conforme se pudo comprobar de la revisión práctica de casos efectuada, es el mismo juez, en mérito de sus facultades directivas, quién frecuentemente ordena que se retire una pregunta, sin haber mediado iniciativa de parte, debiendo el abogado que interroga reformular. Fruto de las facultades oficiosas, el magistrado ejerce objeciones directamente, anticipando la objeción que la parte contraria podría haber realizado ante una pregunta inadmitida. Su dictación debe ser entendida como una resolución, en la que las partes mantienen el derecho a manifestar oposición fundada en su contra.

Dicho ejercicio práctico de la potestad jurisdiccional oficiosa pudo ser verificado de forma frecuente en los casos revisados, significando de forma comparativa un tercio de las oportunidades totales en que una pregunta era inadmitida.

Tabla 3: Cantidad de preguntas inadmitidas según origen. Porcentajes totales.

\begin{tabular}{|l|c|c|}
\hline \multicolumn{1}{|c|}{ Preguntas Inadmitidas } & Cantidad & Porcentaje \\
\hline $\begin{array}{l}\text { Incidente de objeción que solicita una pregunta sea } \\
\text { inadmitida }\end{array}$ & 159 & $70,9 \%$ \\
\hline $\begin{array}{l}\text { Medida judicial oficiosa que ordena una pregunta sea } \\
\text { inadmitida }\end{array}$ & 65 & $29,1 \%$ \\
\hline
\end{tabular}

Fuente: Elaboración propia.

Esta estadística refuerza una comprensión oficiosa de nuestro proceso

\footnotetext{
${ }^{70}$ DíAz, cit. (n. 9), p. 147.

${ }^{71}$ Ver supra. 3., Preguntas no admitidas, d) Confusas.

${ }^{72}$ Academia Judicial, cit. (n. 69), p. 96.
} 
laboral actual, donde las potestades jurisdiccionales devienen en la práctica en un ejercicio activo en el control de información de las declaraciones testimoniales. En definitiva, la práctica forense observada nos confirma un juez protagónico en el desarrollo de la declaración testimonial, en contraposición a la actuación de los litigantes, que, como se indicó, no ejercieron con la frecuencia esperada el control de acceso de información en el interrogatorio de testigos. ${ }^{73}$ Así, permanece la interrogante sobre si se justifica esta acción inhibitoria judicial en los casos que se manifieste de forma previa a la voluntad de las partes.

En tal sentido, no puede desconocerse que la reforma que sustituyó el procedimiento laboral del Libro $\mathrm{V}$ del Código del Trabajo, consagró una serie de potestades y atribuciones judiciales que renovaron la concepción de la judicatura laboral hacia un magistrado "comprometido y proactivo en el devenir del litigio". ${ }^{74}$

Sin querer abordar íntegramente esta reiterada discusión procesal que irrumpe ante la intromisión oficiosa del juez, debe tenerse en consideración la serie de advertencias que ha efectuado la doctrina garantista sobre las contravenciones al debido proceso que pudieran sucederse en el ejercicio de un interrogatorio judicial. ${ }^{75}$ Por su parte, escaso comentario doctrinal ha existido respecto de la facultad oficiosa de inadmitir preguntas en el interrogatorio de testigos.

No se puede desconocer que, de forma práctica, la acción judicial de oficio que anticipa la objeción de preguntas, termina por subsidiar la debilidad en el ejercicio de los derechos litigiosos de la parte a la que le competía su iniciativa. Con razón se ha dicho que el acto de interrogar nunca es "puramente neutral", de la misma forma, tampoco se entiende lo sea, la facultad de impedir la realización de una pregunta de oficio en medio de la

\footnotetext{
${ }^{73}$ Ver supra. III. Características de la inadmisión de Preguntas en el Interrogatorio Laboral. 1) Frecuencia.

${ }^{74}$ BaLic, cit. (n. 3), p. 113.

${ }^{75}$ Alvarado, Adolfo, "La imparcialidad judicial y el sistema inquisitivo de juzgamiento", Revista Ratio Iuris, 2014, Vol. $9 \mathrm{~N}^{\circ} 18$, pp. 207-235; en Alvarado, A.; Montero, J.; Picazo, I. (coords.), Proceso civil e ideología, Tirant Lo Blanch, Valencia, 2011, $2^{\text {a }}$ edición, pp. 217-246; Palavecino, cit. (n. 64), pp. 151-176; Ruay, cit. (n. 54); Balic, cit. (n. 3), pp. 107-132; Palomo, Diego; Matamala, Pedro, "Prueba, inmediación y potestades en el Proceso Laboral: Observaciones críticas y apelación al equilibrio", Revista de Derecho Universidad Católica del Norte, 2012, Vol. 19, № 2, pp. 237-274.
} 
declaración de un testigo. ${ }^{76}$

Dicha actuación tiene el efecto innegable de debilitar el contradictorio, puesto que desvanece su dialéctica adversarial, pudiendo perjudicar tanto la estrategia como la teoría del caso de cualquiera de las partes. ${ }^{77}$ Junto con ello, suple la pasividad del litigante contrario quién no ejerció la incidencia debida ante la locución de una pregunta, o bien, por el contrario, pudiese introducir controversia donde no existiese. ${ }^{78}$ Así, la desproporción producida contraviene las bases del modelo adversarial cuya constitución debe suponer una base ecuánime para el ejercicio de los derechos litigiosos.

La facultad judicial de preguntar y de resolver cuáles serán las preguntas admisibles en los interrogatorios existe y no puede ser alterada. ${ }^{79}$ Sin embargo, no debiera considerarse como una potestad judicial de uso frecuente, la que se ejerce deteniendo la comisión de una pregunta que no ha sido objetada por las partes. La igualdad procesal se vulnera cuando "una parte obtiene en el curso del juicio lo que sin iniciativa oficiosa no hubiere obtenido, con independencia del móvil subjetivo que haya tenido el juez" para impedir la realización de la pregunta. ${ }^{80}$ En efecto, correspondiendo al ejercicio de una facultad directiva general y no una potestad normativa expresa, existirá siempre el cuestionamiento formal válido sobre qué hubiese sucedido en el curso del interrogatorio, si la contraria hubiese sido la que objeta o si el testigo hubiese respondido dicha pregunta. ${ }^{81}$

Ante dicha controversia cabe sostener que corresponderá nuevamente interpretar de forma restrictiva dicha facultad jurisdiccional ante el menor atisbo que su ejercicio atente contra la imparcialidad en el interrogatorio. ${ }^{82}$

\footnotetext{
${ }^{76}$ RÚA, cit. (n. 5), p. 37.

${ }^{77}$ Ibíd.

${ }^{78}$ Decap, cit. (n. 28), p. 116.

${ }^{79}$ Como contrapartida a este derecho a preguntar se encuentra el de objetar las preguntas que el juez realice, tema que no fue tratado por su extensión en la presente monografía. En este punto se seguirá lo sostenido en Palomo, Diego; Matamala, Pedro, "Juez y Parte. El compromiso espiritual del juez en el interrogatorio de testigos en el juicio laboral oral y sus necesarios límites", Revista Ius et Praxis, 2011, Vol. 17, N², pp. 485-504.

${ }^{80}$ BALIC, cit. (n. 3), p. 117.

${ }^{81}$ En este sentido, el juez debiera conservar pasividad, que resulta ser una de las garantías que componen el principio del debido proceso. Existe el derecho a un juez imparcial, característica que el sentenciador perdería al momento de subsidiar a alguna de las partes durante la rendición de la prueba y que, por cierto, contribuiría a generar un desequilibrio en la relación procesal. PALOMO, cit. (n. 12), p. 221.

${ }^{82}$ RuAy, Francisco, "Análisis crítico de las potestades atípicas del juez laboral ante el principio de
} 
El escueto tratamiento del Código del Trabajo sobre qué tipos de preguntas pueden objetarse en el interrogatorio de testigos, ha generado la existencia de diversas clasificaciones doctrinales, sin existir ninguna versión conclusiva de la denominación de las mismas. Por consiguiente, a través del presente ejercicio del "método de casos", pudieron efectuarse una extensa serie de revisiones de audios de audiencias de juicio, que buscaron analizar la interposición de objeciones en el proceso laboral:

1.- El ejercicio de inadmitir preguntas, mantiene en la práctica, un desarrollo considerablemente más extenso que el regulado de forma estricta en el artículo $454 \mathrm{~N}^{\circ} 6$, que correspondería sólo a las preguntas inductivas (asertivas) e impertinentes. En efecto, de la investigación realizada se encontraron una amplia variedad de preguntas objetadas en base a fundamentos que transitan desde normas aledañas del mismo Código del Trabajo a normas supletorias del Código de Procedimiento Civil, e inclusive por la aplicación de principios generales.

A partir de ello, se pudo afirmar con sustento, cuáles son los tipos de preguntas inadmitidas más frecuentes en un interrogatorio laboral. Las preguntas que fueron solicitada su inadmisión por los litigantes, y que al menos se repitieron una vez, recibieron los siguientes rótulos: "inadmisible", "confusa" "reiterativa" o "coercitiva"; más las tradicionales: "inductiva/ sugestiva" e "impertinente".

Su determinación no impidió que cada una de ellas, pudieran ser objeto de análisis que precisará los alcances de cada prohibición:

i) Se expresó una opinión contraria a la interposición de objeciones basadas en principios o "conceptos indeterminados", tal como se observó con ocasión de las preguntas "reiterativas" o "confusas". Sin perjuicio de que no se observó cuestionamiento a que las partes recurran a una diversidad de argumentos legales a efectos de solicitar la inadmisión de una pregunta - tales como las que rigen la prueba de absolución de posiciones (artículo $454 \mathrm{~N}^{\circ} 4$ ), las que no rigen por contraposición a la declaración pericial

juridicidad", Revista Chilena de Derecho del Trabajo y de la Seguridad Social, 2014, Vol. 5, N9, pp. 83105; Alvarado, Adolfo, "El enjuiciamiento en material laboral, ¿Debido Proceso? Estudio preliminar”, en: Palomo, D. (Dir.), Proceso y Justicia Laboral: Lecturas a contracorriente, Ediciones Jurídicas de Santiago, Santiago, 2015, pp. 11-26. 
(artículo 409)- sí se expresaron reparos a la fundamentación de incidencias y consecuentes resoluciones, cuando ésta se hacía exclusivamente en base a principios jurídicos. En este sentido, siendo la facultad de interrogar, parte del ejercicio del derecho a la prueba, se entiende no debería verse limitado por la aplicación de supuestas prohibiciones que carezcan de fundamento positivo.

ii) El Código del Trabajo en el mínimo tratamiento a la inadmisión de preguntas alude a la distinción doctrinal entre preguntas "asertiva" e "inductiva". Sin embargo, pudo verificarse que aquella distinción no fue aplicada en ninguno de los pronunciamientos judiciales revisados que resolvieron los incidentes de objeción, siendo denominada de forma unánime como "inductiva" o "sugestiva".

iii) Al tratar las preguntas denominadas "inadmisibles", se abordó la discusión sobre la limitación fáctica de las formas interrogativas que involucraban aspectos jurídicos o técnicos. A partir de ello, se sostuvo que pese a no existir la figura doctrinal de "testigo experto", no se debiera considerar limitar el interrogatorio que haya derivado en particularidades técnicas, que el testigo pudo espontáneamente contestar debido a su experiencia y conocimiento.

2.- De lo expuesto, se pudo constatar que la interposición de objeciones por parte de los litigantes laborales, no correspondía a un incidente de comisión abundante en las declaraciones testimoniales observadas. En contraposición a lo señalado, se observó comparativamente que los magistrados, en su rol directivo del proceso, ordenaron la inadmisión oficiosa de numerosas preguntas. Las resoluciones que ordenaron el retiro de una determinada interrogante, previo a la intervención del abogado contrario, ascendieron a casi un tercio de las objeciones que ejercieron las partes en total, lo que no deja de ser una cantidad significativa si pensamos que corresponde a una facultad excepcional.

Al respecto, se criticó la intromisión judicial en el interrogatorio, que, sin la solicitud o controversia de las partes, inadmitía la realización de una determinada pregunta. Antes de actuar de oficio interrumpiendo el curso de una prueba testimonial, se entiende que resultaría más acorde al respeto del contradictorio, que el juzgador no se pronunciase sino hasta que se haya ejercido una incidencia de objeción por alguno de los litigantes. Si dicha facultad oficiosa es ejercida sólo de forma restringida, se asegurará de forma plena la imparcialidad judicial y las partes conservarán debidamente 
su derecho de incidentar respecto de una pregunta, manteniendo el control del ingreso de la información en el probatorio.

3.- Por último, de la observación general procesal de los casos estudiados, debe concordarse que mantener una posición no activa en la interposición de incidentes de objeción, cede una poderosa facultad a la actividad interrogativa del abogado de la contraparte e impacta la valoración de la prueba testimonial que realizará posteriormente el sentenciador.

Una revisión estricta al tratamiento normativo del Código del Trabajo, permitirá concluir que el legislador ha buscado que la prueba testimonial presentada en un juicio sea efectivamente controvertida y refutada por las partes en relación con las técnicas de interrogación que ejecuten. En este sentido, el acto de incidentar solicitando que no se admita la realización de una pregunta en el interrogatorio, corresponde a un mecanismo imprescindible para el control de la calidad de la información que ingresa al juicio laboral.

En concreto, corresponde que el incidente de objeción sea revalorado como un instrumento procesal de convicción, debiendo ser usado de forma óptima por las partes a efectos de aquilatar el nivel de fiabilidad de los relatos que los testigos presentan. Su falta de ejercicio, significará tolerar muchas veces, que, de forma improcedente, ingresen antecedentes que serán objeto de la decisión del tribunal. Queda de manifiesto que corresponde a una herramienta necesaria para encuadrar la declaración testimonial a los límites del proceso y coartar a la parte contraria o inclusive al juez, a ceñir su labor a preguntas admisibles.

El acto de objetar, no debe ser confundido con una posición obstruccionista; corresponde a un derecho base sobre el que descansa el modelo contradictorio de litigios judiciales. Por ningún motivo se busca favorecer un interrogatorio marcado por interrupciones, que dificulten la comprensión íntegra del mismo. Por el contrario, se busca optimizar la forma de interrogación oral de los testigos para mejorar el contenido probatorio del proceso, habida cuenta que la plena ejecución del contradictorio testimonial, enriquece su resultado; siendo el fundamento último de la objeción, las normas del debido proceso. 


\section{BIBLIOGRAFÍA CITADA}

Abel, Xavier; Picó, Joan, El Interrogatorio de Testigos, Bosch, Barcelona, 2008, Vol. 2.

Academia Judicial, Manual de Juicio del Trabajo, Academia Judicial, Santiago, 2017, 2a edición, 278 p.

Alcaíno, Rodrigo; Cortés, Matías, Curso Elemental de Litigación Oral, Editorial Jurídica de Chile, Santiago, 2020, 259 p.

Alvarado, Adolfo, La Prueba Judicial. Reflexiones Críticas sobre la Confirmación Procesal, Tirant Lo Blanch, Valencia, 2006.

Alvarado, A.; Montero, J.; Picazo, I. (coords.), Proceso civil e ideología, Tirant Lo Blanch, Valencia, 2011, $2^{\mathrm{a}}$ edición, pp. 217-246.

Alvarado, Adolfo, "La imparcialidad judicial y el sistema inquisitivo de juzgamiento", Revista Ratio Iuris, 2014, Vol. 9 Nº18, pp. 207-235

Alvarado, Adolfo, "El enjuiciamiento en material laboral, ¿Debido Proceso? Estudio preliminar", en: PALomo, D. (Dir.), Proceso y Justicia Laboral: Lecturas a contracorriente, Ediciones Jurídicas de Santiago, Santiago, 2015.

Álvarez, Magdalena; Rosseti, Andrés (coords.), Derecho a la Vida: Un análisis desde el método de casos, Editorial Advocatus, Córdoba, 2005.

BALIC, Cristóbal, "Intervención del Juez Laboral en el interrogatorio de testigos: Iniciativa probatoria oficiosa y debido proceso", Revista Chile de Derecho del Trabajo y de la Seguridad Social, 2015, Vol. 6, N 11, pp. 107-132.

Baytelman, Andrés; Duce, Mauricio, Litigación Penal. Juicio Oral y Prueba, Grupo Editorial Ibáñez, Bogotá, 2014, 349 p.

Bronstern, Arturo, La Subordinación o Dependencia en el Contrato de Trabajo, Lexis Nexis, Santiago, 2005, 235 p.

Carnelutti, Francesco, Cómo se hace un Proceso, Editorial Temis, Buenos Aires, 2018, 159 p.

Contreras, Cristián, La Valoración de la Prueba de Interrogatorio, Marcial Pons Madrid, 2015, 393 p.

Contreras, Cristián, "Valoración de las pruebas de declaración de personas en segunda instancia" Tesis Doctoral, dirección del profesor Jordi Nieva Fenoll, Universidad de Barcelona, Barcelona, 2015.

Couture, Eduardo J., Los Mandamientos del Abogado, Ed. Coyoacán, México D.F., 2013.

DeCAP, Mauricio, "La prueba de los hechos en el proceso penal", Libromar, Santiago, 2019, Tomo I.

DíAz, Marcela, Manual de Procedimiento del Trabajo, Librotecnia, Santiago, 2018, $2^{a}$ edición actualizada.

Dosi, Ettore, La Prueba testimonial. Estructura y funciones, Eds. Olejnik, Buenos Aires, 2016, 131 pp. 
Fernández, Oscar, Arte y Técnica del Interrogatorio, Thomson Reuters Aranzadi, Navarra, 2017, 190 p.

FERNÁNDEZ, Óscar, Máximas del Interrogatorio, Thomson Reuters - Aranzadi, Navarra, 2019.

Fernández, Raúl, La Prueba en el Proceso Laboral, Tirant Lo Blanch, Valencia, 2020, edición digital, 1072 p.

FerRater, José, Diccionario de Filosofia Abreviado, Editorial Sudamericana, Buenos Aires, 1975, 410 p.

García, Julio; Romero, Luis; GonzÁlez, Florentino, La Técnica del Interrogatorio, Editorial Rasche, Madrid, 2012, $3^{\text {a }}$ edición.

Garrido, Carlos, Examen y Contraexamen de Testigos en el Proceso Penal, Editorial Metropolitana, Santiago, 2018.

LAIDA, Julia, "El Método del estudio de casos como estrategia metodológica para desarrollar habilidades investigativas en la formación del jurista", Iuris Tantum - Revista Boliviana de Derecho, 2012, Vol. 13, pp. 60-101.

Lorenzo, Leticia, Manual de Litigación, Ediciones Didot, Buenos Aires, 2019, $7^{\text {a }}$ edición, 241 p.

Marinoni, Luiz G.; Cruz, Sergio, La prueba, Thomson Reuters, Santiago, 2015, 453 p.

Mazzoni, Giuliana, ¿Se puede creer a un testigo? El testimonio y las trampas de la memoria, Editorial Trotta, Madrid, 2020.

Micheletti, Pablo, Litigación oral desde el lenguaje corporal, Editorial Librería Cívica, Santa Fe, 2019.

Ortega, Waldo, Litigación Oral para el Proceso Penal, Editorial Universidad Católica de la Santísima Concepción, Santiago, 2012.

Palavecino, Claudio; Ruay, Francisco, "El principio de la buena fe en los procedimientos laborales frente al principio de legalidad o juridicidad. ¿Tienen los jueces del trabajo facultades tácitas o implícitas?", en: Palomo, D. (Dir.), Proceso y Justicia Laboral: Lecturas a Contracorriente, Ediciones Jurídicas de Santiago, Santiago, 2015.

Palavecino, Claudio, "La Reforma Procesal Laboral Chilena: Una visión crítica desde el Garantismo Procesal”, Revista Laboral Chilena, 2012, № 208, pp. 59-68;

Palomo, Diego(Dir.), Procesoy Justicia Laboral: Lecturas a Contracorriente, Editorial Jurídica de Santiago, 2015, Tomo I.

Palomo, Diego; Matamala, Pedro, "Prueba, inmediación y potestades en el Proceso Laboral: Observaciones críticas y apelación al equilibrio", Revista de Derecho Universidad Católica del Norte, 2012, Vol. 19, ํ 2, pp. 237-274.

Palomo, Diego; Matamala, Pedro, "Juez y Parte. El compromiso espiritual del juez en el interrogatorio de testigos en el juicio laboral oral y sus necesarios límites", Revista Ius et Praxis, 2011, Vol. 17, N², pp. 485-504. 
Palomo, Diego, "Segunda Parte Procedimiento de Aplicación General", en Delgado, J.; Córtez, G.; Palomo, D. (Eds.), Proceso Laboral, Thomson Reuters, Santiago, 2021.

PÉrez, Juan, "La Enseñanza del Derecho en Estados Unidos", Doxa (Universidad de Alicante), 1992, N¹2.

RETAMALES, Romina, "Herramientas tecnológicas en la prueba testimonial en la Reforma Procesal Civil", Memoria para optar al grado de Licenciado en Ciencias Jurídicas y Sociales, dirigida por la Profesora Lorena Donoso, Universidad de Chile, Santiago, 2017.

RúA, Gonzalo, Examen Directo de Testigos, Ediciones Didot, Santiago, 2015, $3^{\mathrm{a}}$ edición, 200 p.

RuAY, Francisco, “Análisis crítico de las potestades atípicas del juez laboral ante el principio de juridicidad", Revista Chilena de Derecho del Trabajo y de la Seguridad Social, 2014, Vol. 5, N9, pp. 83-105.

RuAy, Francisco, Las Potestades Atípicas del Juez Laboral: Una lectura crítica, Ediciones Jurídicas de Santiago, Santiago, 2017, 272 p.

Sotelo, Cipriano, Práctica Forense del Contrainterrogatorio en el Juicio Oral, Editorial Flores, México D.F., 2015.

Stern, Friedrich, El Conocimiento Privado del Juez, traducción de Andrés de la Oliva Santos, Editorial Universitaria Ramón Areces, Madrid, 1990.

STÜRNER, Rolf, "La obtención de información probatoria en el proceso civil", Revista de Derecho Pontificia Universidad Católica de Valparaíso, 2008, Vol. 30, pp. 243-262.

TARUfFo, Michele, Simplemente la verdad: El Juez y la Construcción de los Hechos, Marcial Pons, Madrid, 2010, 324 p.

UrzúA, Romina, Tutela Laboral: Análisis crítico desde el método de casos, Libromar, Santiago, 2017.

Vial, Pelayo, Técnicas y fundamentos en el contraexamen en el Proceso Penal Chileno, Librotecnia, Santiago, 2006.

\section{ANEXO}

A continuación, se individualizan las causas judiciales consultadas, con indicación del número de testigos que declararon en las respectivas audiencias de juicio, cuyas declaraciones fueron analizadas para el desarrollo de este trabajo. Los audios respectivos son de público acceso, y pueden consultarse en la Oficina Judicial Virtual del Poder Judicial (https://oficinajudicialvirtual.pjud.cl/).

1. Primer Juzgado de Letras del Trabajo de Santiago, RIT O-5-2018, 2 testigos. 
2. Primer Juzgado de Letras del Trabajo de Santiago, RIT O-24-2018, 4 testigos.

3. Primer Juzgado de Letras del Trabajo de Santiago, RIT O-31-2018, 3 testigos.

4. Primer Juzgado de Letras del Trabajo de Santiago, RIT O-46-2018, 2 testigos.

5. Primer Juzgado de Letras del Trabajo de Santiago, RIT O-51-2018, 2 testigos.

6. Primer Juzgado de Letras del Trabajo de Santiago, RIT O-61-2018, 4 testigos.

7. Primer Juzgado de Letras del Trabajo de Santiago, RIT O-104-2018, 1 testigo.

8. Primer Juzgado de Letras del Trabajo de Santiago, RIT O-109-2018, 5 testigos.

9. Primer Juzgado de Letras del Trabajo de Santiago, RIT O-113-2018, 1 testigo.

10. Primer Juzgado de Letras del Trabajo de Santiago, RIT O-115-2018, 1 testigo.

11. Primer Juzgado de Letras del Trabajo de Santiago, RIT O-126-2018, 4 testigos.

12. Primer Juzgado de Letras del Trabajo de Santiago, RIT O-136-2018, 5 testigos.

13. Primer Juzgado de Letras del Trabajo de Santiago, RIT O-142-2018, 2 testigos.

14. Primer Juzgado de Letras del Trabajo de Santiago, RIT O-146-2018, 2 testigos.

15. Primer Juzgado de Letras del Trabajo de Santiago, RIT O-162-2018, 2 testigos.

16. Primer Juzgado de Letras del Trabajo de Santiago, RIT O-168-2018, 2 testigos.

17. Primer Juzgado de Letras del Trabajo de Santiago, RIT O-169-2018, 3 testigos.

18. Primer Juzgado de Letras del Trabajo de Santiago, RIT O-175-2018, 1 testigo.

19. Primer Juzgado de Letras del Trabajo de Santiago, RIT O-177-2018, 1 testigos.

20. Primer Juzgado de Letras del Trabajo de Santiago, RIT O-204-2018, 2 testigos.

21. Primer Juzgado de Letras del Trabajo de Santiago, RIT O-219-2018, 2 testigos.

22. Primer Juzgado de Letras del Trabajo de Santiago, RIT O-220-2018, 3 
testigos.

23. Primer Juzgado de Letras del Trabajo de Santiago, RIT O-241-2018, 2 testigos.

24. Primer Juzgado de Letras del Trabajo de Santiago, RIT O-247-2018, 3 testigos.

25. Primer Juzgado de Letras del Trabajo de Santiago, RIT O-248-2018, 4 testigos.

26. Primer Juzgado de Letras del Trabajo de Santiago, RIT O-250-2018, 3 testigos.

27. Primer Juzgado de Letras del Trabajo de Santiago, RIT O-258-2018, 2 testigos.

28. Primer Juzgado de Letras del Trabajo de Santiago, RIT O-263-2018, 4 testigos.

29. Primer Juzgado de Letras del Trabajo de Santiago, RIT O-276-2018, 2 testigos.

30. Primer Juzgado de Letras del Trabajo de Santiago, RIT O-295-2018, 2 testigos.

31. Primer Juzgado de Letras del Trabajo de Santiago, RIT O-310-2018, 6 testigos.

32. Primer Juzgado de Letras del Trabajo de Santiago, RIT O-326-2018, 1 testigo.

33. Primer Juzgado de Letras del Trabajo de Santiago, RIT O-334-2018, 3 testigos.

34. Primer Juzgado de Letras del Trabajo de Santiago, RIT O-343-2018, 3 testigos.

35. Primer Juzgado de Letras del Trabajo de Santiago, RIT O-351-2018, 3 testigos.

36. Primer Juzgado de Letras del Trabajo de Santiago, RIT O-390-2018, 2 testigos.

37. Primer Juzgado de Letras del Trabajo de Santiago, RIT O-392-2018, 1 testigos.

38. Primer Juzgado de Letras del Trabajo de Santiago, RIT O-395-2018, 3 testigos.

39. Primer Juzgado de Letras del Trabajo de Santiago, RIT O-409-2018, 3 testigos.

40. Primer Juzgado de Letras del Trabajo de Santiago, RIT O-410-2018, 1 testigo.

41. Primer Juzgado de Letras del Trabajo de Santiago, RIT O-415-2018, 2 testigos.

42. Primer Juzgado de Letras del Trabajo de Santiago, RIT O-424-2018, 2 testigos. 
43. Primer Juzgado de Letras del Trabajo de Santiago, RIT O-438-2018, 4 testigos.

44. Primer Juzgado de Letras del Trabajo de Santiago, RIT O-445-2018, 1 testigos.

45. Primer Juzgado de Letras del Trabajo de Santiago, RIT O-448-2018, 2 testigos.

46. Primer Juzgado de Letras del Trabajo de Santiago, RIT O-450-2018, 4 testigos.

47. Primer Juzgado de Letras del Trabajo de Santiago, RIT O-453-2018, 3 testigos.

48. Primer Juzgado de Letras del Trabajo de Santiago, RIT O-455-2018, 3 testigos.

49. Primer Juzgado de Letras del Trabajo de Santiago, RIT O-458-2018, 3 testigos.

50. Primer Juzgado de Letras del Trabajo de Santiago, RIT O-477-2018, 2 testigos.

51. Primer Juzgado de Letras del Trabajo de Santiago, RIT O-483-2018, 2 testigos.

52. Primer Juzgado de Letras del Trabajo de Santiago, RIT O-497-2018, 3 testigos.

53. Primer Juzgado de Letras del Trabajo de Santiago, RIT O-1012-2018, 3 testigos.

54. Primer Juzgado de Letras del Trabajo de Santiago, RIT O-1043-2018, 3 testigos.

55. Primer Juzgado de Letras del Trabajo de Santiago, RIT O-1050-2018, 3 testigos.

56. Primer Juzgado de Letras del Trabajo de Santiago, RIT O-1061-2018, 4 testigos.

57. Primer Juzgado de Letras del Trabajo de Santiago, RIT O-1078-2018, 3 testigos.

58. Primer Juzgado de Letras del Trabajo de Santiago, RIT O-1080-2018, 5 testigos.

59. Primer Juzgado de Letras del Trabajo de Santiago, RIT O-1086-2018, 4 testigos.

60. Primer Juzgado de Letras del Trabajo de Santiago, RIT O-1099-2018, 2 testigos.

61. Primer Juzgado de Letras del Trabajo de Santiago, RIT O-1108-2018, 1 testigo.

62. Primer Juzgado de Letras del Trabajo de Santiago, RIT O-1109-2018, 2 testigos.

63. Primer Juzgado de Letras del Trabajo de Santiago, RIT O-1114-2018, 3 
testigos.

64. Primer Juzgado de Letras del Trabajo de Santiago, RIT O-1117-2018, 1 testigo.

65. Primer Juzgado de Letras del Trabajo de Santiago, RIT O-1120-2018, 4 testigos.

66. Primer Juzgado de Letras del Trabajo de Santiago, RIT O-3136-2019, 6 testigos.

67. Primer Juzgado de Letras del Trabajo de Santiago, RIT O-3153-2019. 2 testigos.

68. Primer Juzgado de Letras del Trabajo de Santiago, RIT O-3162-2019, 1 testigo.

69. Primer Juzgado de Letras del Trabajo de Santiago, RIT O-3212-2019, 1 testigo.

70. Primer Juzgado de Letras del Trabajo de Santiago, RIT O-3254-2019, 3 testigos.

71. Primer Juzgado de Letras del Trabajo de Santiago, RIT O-3273-2019, 1 testigo.

72. Primer Juzgado de Letras del Trabajo de Santiago, RIT O-3318-2019, 1 testigo.

73. Primer Juzgado de Letras del Trabajo de Santiago, RIT O-3360-2019, 5 testigos.

74. Primer Juzgado de Letras del Trabajo de Santiago, RIT O-3367-2019, 2 testigos.

75. Primer Juzgado de Letras del Trabajo de Santiago, RIT O-3373-2019, 3 testigos.

76. Primer Juzgado de Letras del Trabajo de Santiago, RIT O-3395-2019, 4 testigos.

77. Primer Juzgado de Letras del Trabajo de Santiago, RIT O-3412-2019, 4 testigos.

78. Primer Juzgado de Letras del Trabajo de Santiago, RIT O-3423-2019, 1 testigo.

79. Primer Juzgado de Letras del Trabajo de Santiago, RIT O-3440-2019, 4 testigos.

80. Primer Juzgado de Letras del Trabajo de Santiago, RIT O-3466-2019, 3 testigos.

81. Primer Juzgado de Letras del Trabajo de Santiago, RIT O-3495-2019, 2 testigos.

82. Primer Juzgado de Letras del Trabajo de Santiago, RIT O-3497-2019, 2 testigos.

83. Primer Juzgado de Letras del Trabajo de Santiago, RIT O-3011-2019, 3 testigos. 
84. Primer Juzgado de Letras del Trabajo de Santiago, RIT O-3033-2019, 2 testigos.

85. Primer Juzgado de Letras del Trabajo de Santiago, RIT O-3060-2019, 4 testigos.

86. Primer Juzgado de Letras del Trabajo de Santiago, RIT O-3062-2019, 3 testigos.

87. Primer Juzgado de Letras del Trabajo de Santiago, RIT O-3085-2019, 1 testigo.

88. Primer Juzgado de Letras del Trabajo de Santiago, RIT O-2980-2019, 2 testigos.

89. Primer Juzgado de Letras del Trabajo de Santiago, RIT O-2937-2019, 2 testigos.

90. Primer Juzgado de Letras del Trabajo de Santiago, RIT O-2934-2019, 1 testigo.

91. Primer Juzgado de Letras del Trabajo de Santiago, RIT O-2920-2019, 1 testigo.

92. Primer Juzgado de Letras del Trabajo de Santiago, RIT O-2899-2019, 7 testigos.

93. Primer Juzgado de Letras del Trabajo de Santiago, RIT O-2898-2019, 6 testigos.

94. Primer Juzgado de Letras del Trabajo de Santiago, RIT O-2886-2019, 2 testigos.

95. Primer Juzgado de Letras del Trabajo de Santiago, RIT O-2867-2019, 3 testigos.

96. Primer Juzgado de Letras del Trabajo de Santiago, RIT O-2844-2019, 4 testigos.

97. Primer Juzgado de Letras del Trabajo de Santiago, RIT O-2831-2019, 2 testigos.

98. Primer Juzgado de Letras del Trabajo de Santiago, RIT O-2829-2019, 6 testigos.

99. Primer Juzgado de Letras del Trabajo de Santiago, RIT O-2750-2019, 4 testigos.

100. Primer Juzgado de Letras del Trabajo de Santiago, RIT O-2742-2019, 2 testigos. 